\title{
Apresentação
}

\section{Olhares sobre patrimônio industrial e urbano}

Nem sempre revistas de área, com pauta ampla e multidisciplinar como a Revista $\mathrm{CPC}$, logram constituir um volume mais coeso tematicamente. De certo modo, o número 14 converge para um campo comum de questões acerca do patrimônio urbano e do patrimônio industrial. Motivados por inquietações ora teóricas, ora político-institucionais, as contribuições aqui reunidas sugerem a valorização do tema nas pesquisas, debates e ações no campo do patrimônio.

O artigo de Manoela Rossinetti Rufinoni, "Os estudos de Estética Urbana e a percepção da cidade artefato no alvorecer do século XX", adentra a questão pela história primitiva da literatura especializada. Retomando duas das principais contribuições ao campo da Estética Urbana, os livros de Camillo Sitte e Charles Buls, a autora sugere neles encontrar mais do que uma resposta disciplinar ao desenvolvimento urbano contemporâneo. Ao percorrer seus modos de aproximação à forma edilícia e ao fazer tradicional das cidades, propõe-se um olhar para o patrimônio urbano como campo visual e histórico e como base das ações sobre os tecidos em transformação.

Em outra direção, aponta o artigo de Angela Rosch Rodrigues, "Patrimônio industrial e os órgãos de preservação na cidade de São Paulo", que propõe desta vez examinar o processo de reconhecimento dos remanescentes industriais na cidade de São Paulo pelas três esferas de preservação (municipal, estadual e federal). Ao analisar as instruções de tombamento e os critérios de valor mobilizados pelos órgãos competentes nas últimas duas décadas, o trabalho sugere algumas chaves de entendimento acerca do processo, seus objetos e significados.

Também voltado ao entendimento das políticas patrimoniais é o artigo de Marcelo Cardoso de Paiva, "O patrimônio cultural do $A B C$ paulista: horizontes possíveis nas políticas municipais de preservação". A análise agora se detém na institucionalização dos conselhos municipais de patrimônio no ABC como arenas locais de representação, intermediação e formulação de políticas urbanas. Além de avaliar seu papel e funcionamento, trata-se de pensar os sentidos tomados pela 
preservação naquele contexto, seus objetos de atenção e o impacto de suas ações sobre uma paisagem urbana profundamente afetada pela atividade industrial.

O texto de Julio Cesar Ribeiro Sampaio, "Desafios da proteção do patrimônio cultural industrial de Juiz de Fora", também se concentra em uma região marcada pela industrialização, no caso pelo primeiro ciclo industrial no país, no interior do qual a cidade emergiu como um de seus principais polos. A estratégia de enfrentamento das políticas de preservação é a análise de um exemplar paradigmático: a Fábrica dos Ingleses, fundada em 1883 e que após o seu fechamento um século depois, foi abandonada e parcialmente demolida até ser finalmente tombada pela Prefeitura em 2003/4. É com base neste caso, que se sugere uma reflexão mais geral acerca dos processos de tombamento, conservação e utilização do patrimônio industrial.

A seção Coleções e Acervos é aqui representada por uma discussão em torno da Cité Nationale de I'Histoire de I'Immigration, instituição criada em 2007 e sediada em Paris. Partindo de uma análise de sua concepção original, Andrea Delaplace se detém na análise do edifício eleito para abrigar a instituição e do projeto de intervenção proposto. Na seção Conservação e Restauração, por sua vez, incluímos um estudo minucioso de um trabalho de restauro empreendido sobre um altar portátil português. De autoria de Daniela Soares Morgadinho e Fernando dos Santos Antunes, o artigo contempla um levantamento criterioso do bem em questão, bem como a descrição e avaliação das metodologias adotadas, dos procedimentos de restauro e seus resultados.

Entre as notícias aqui incluídas, destacamos a entrevista realizada com o antropólogo Antonio Augusto Arantes por Wania Bertinato e Luiz Matthes acerca da criação e primeiro ciclo de ações do CONDEPACC em Campinas. Por fim, um estudo das condições de conservação do Monumento a Ramos de Azevedo, localizado na Cidade Universitária Armando Sales de Oliveira da USP, realizado por Danielle Grossi e Eliane Aparecida Del Lama.

José Tavares Correia de Lira 